\title{
Research on in-plane lateral performance of a new-type composite timber wall panel with cold-formed steel frames
}

\author{
Siya Wang ${ }^{1}$, Jing $L i^{1,2^{*}}$, Zeyu Li $^{1}$, Yanjia Wang ${ }^{1}$ and Ying $X u^{1}$ \\ ${ }^{1}$ School of Civil Engineering and Transportation, South China University of Technology, Guangzhou 510640, P. R. China \\ ${ }^{2}$ State Key Laboratory of Subtropical Building Science, Guangzhou 510640, P. R. China
}

\begin{abstract}
A series of researches on the behaviour of a new structural system, composite timber wall panel with cold-formed steel frames, are investigated under monotonic and reversed cyclic loading. In order to improve the in-plane lateral performance of the composite timber panels, sixteen different optimized composite timber panels were proposed and tested, including increasing the thickness of the sheathings, improvement with steel X-bracings, filling with straw and advance of connection between sheathing and wood framing. The main objective of the investigation is to explore the pervasive mode of failure, determine the quantification of the improvement in lateral performance of these optimized composite timber wall panels and evaluate the benefits of each optimization during the process of failure.
\end{abstract}

\section{Keywords: Optimization, Composite timber wall panels, Cold-formed steel frames, Lateral performance, Monotonic loading, Reversed cyclic loading, Failure mode.}

\section{Introduction}

A new structural system, the cold-formed steel wall panel has become increasingly prevailing as an alternative to the conventional masonry and concrete buildings, in low-rise residential and commercial building. There exists an intriguing characteristic of this structure, that is, its comparatively lighter weight, which rendering them more adequate for earthquake-prone areas rather conventional building systems. Apart from that, the cold-formed steel wall system has merits like recyclability and energy conservation. In addition, their components can be prefabricated in the factory so that they can be handled and constructed at the construction site more easily. [1, 2]

The most usual form among the Cold-Formed Steel Shear Wall (CFSSW) is the "Cold-Formed Steel (CFS) framing sheathed on one side or both sides" , namely a CFS framing with different sheathings applied to one side or both sides of the members. The precedent researches on CFSSWs have put emphasis on their basic mechanic capacities, including axial load bearing capacity [3 - 5] and lateral performance [6 - 9], as well as factors contributing to them. Tian [3] and Vieira Jr [4] reported that axial load bearing capacity of CFS studs could be ameliorated by sheathing materials as well as the type of the board being used. Tian [5] presented an analytical model to predict the axial failure load of CFS studs with sheathing materials in consideration of impacts of the screw spacing, the stud spacing and the characteristics (thickness, Poisson ratio, elastic modulus) of the sheathing materials. Nithyadharan [6] argued that the screw shear strength could determine the wall panel strength. Pan [7] and Ye [8] agreed that the failure of sheathing-to-frame connections was the main reason of degeneration of the in-plane behaviour of a CFSSW. Seim [9] concluded that other than mechanical properties of the sheathings, strength of sheathing-to-frame connections also determines the in-plane lateral performance of CFSSW.

In a nutshell, lateral performance of a CFSSW is mainly determined by the sheathing-to-frame connections, which means mechanical properties of sheathing are hardly taken into account in the structural analysis. Nevertheless, the appearance of a new form CFSSW (Fig.1) could fix this problem, and its performance is invested. The new-type CFSSW includes framing members formed by CFS, composite timber wall panels (CTWP) formed by timber beams and sheathings.
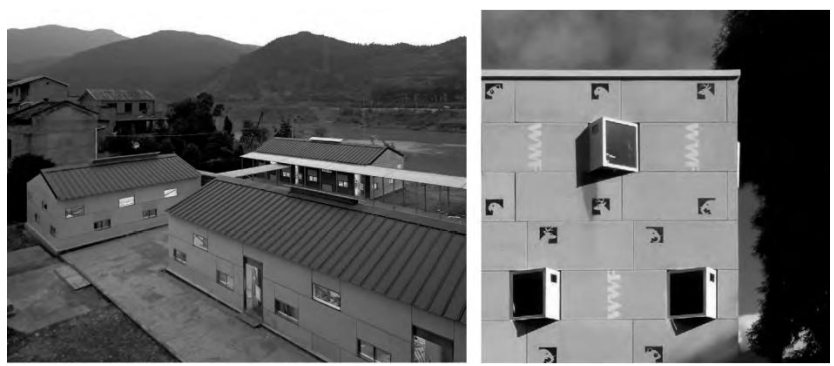

Fig. 1. Practical Projects of CFSSW.

According to our investigation, the lateral

\footnotetext{
* Address correspondence to this author at the School of Civil Engineering and Transportation, South China University of Technology, Guangzhou 510640, P.R. China; Tel: 13570120980; Fax: 020-87114460; E-mail: cvjingli@scut.edu.cn
} 
performance of the new-type CFSSW is mainly determined by CTWPs, which could be inferred from the failure led by CTWPs. [10] In addition, this CFSSW is likely to make ultimate use of the strength of CTWPs. As it is proved that improving the lateral performance of the CTWPs is an effective way to improve the lateral performance of the new-type CFSSW [10], various methods were proposed to optimize the CTWPs, including equipping with steel X-bracings, increasing the thickness of sheathing material, using straw panel as filling, and promoting members' connection, and conducted series of experiments in order to improve the performance of the new-type CFSSW.

This paper first introduces the background information of a series of experiments and the qualitative analysis of these experiments, including CFSSW under monotonic loading and three experiments of CTWPs optimizations under monotonic loading and reversed cyclic loading to analyse the failure mode. Then, these experiments were quantitatively analysed on lateral performance to compare the advantages and disadvantages of different optimization. Finally, the conclusion is drawn.

\section{Experimental studies}

Up to now, four distinct stages of experiments have been finished regarding on factors related to lateral performance of the new-type CFSSW. In total, there are seven types of CTWPs (Type-A, Type-B, Type-C, Type$D$, Type-E, Type-F and Type-G) concluded in this research. Details of the CTWPs are given in Fig.2, Table 1 and 2.

Type-A, Type-B, Type-D, Type-F and Type-G CTWPs are analogous to each other in structure except the details designed for optimization shown in Table 2. Similarly, Type-C and Type-E CTWPs are only different mutually in the position of the X-bracings, which the former ones are outside the wood framing while the latter ones lie between wood framing and straw panel filling. Specially, there are some differences in the arrangement of lateral timber beam between specimens, which are demonstrated in the figures below.

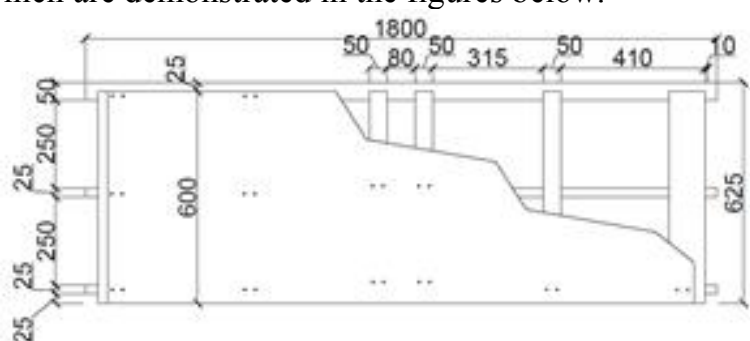

(a) Interior front view of Type- $\mathrm{A} / \mathrm{B} / \mathrm{D} / \mathrm{F} / \mathrm{G}$

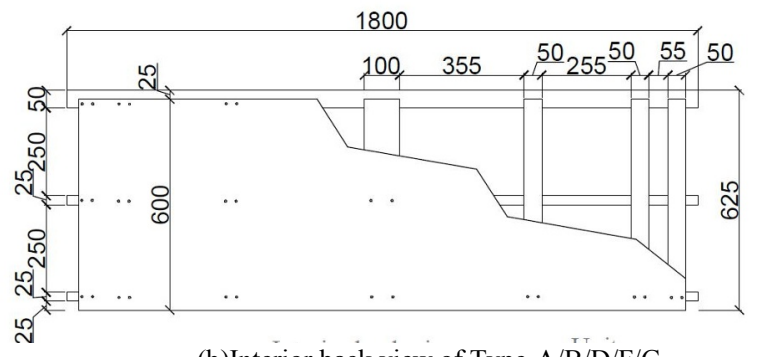

(b)Interior back view of Type- $\mathrm{A} / \mathrm{B} / \mathrm{D} / \mathrm{F} / \mathrm{G}$

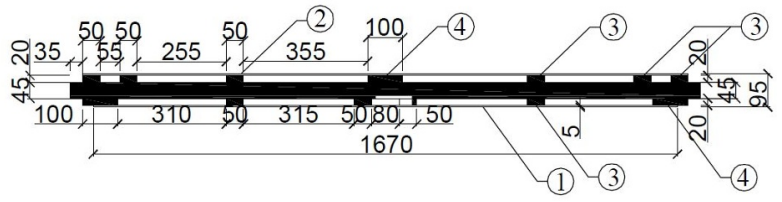

(c)Top view of Type-A/B/D/F/G

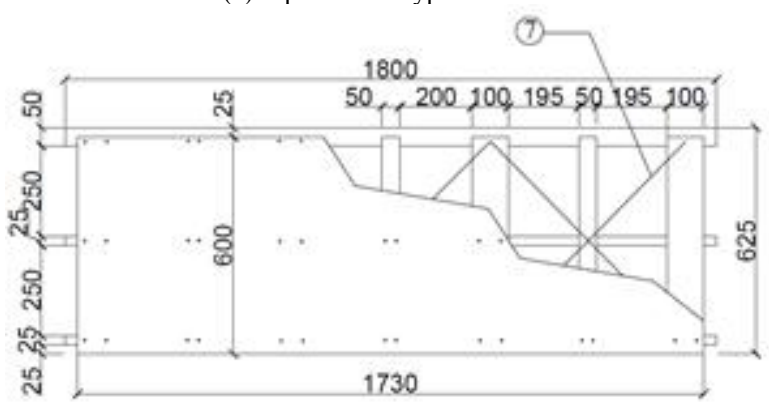

(d) Interior front/back view of Type-C/E

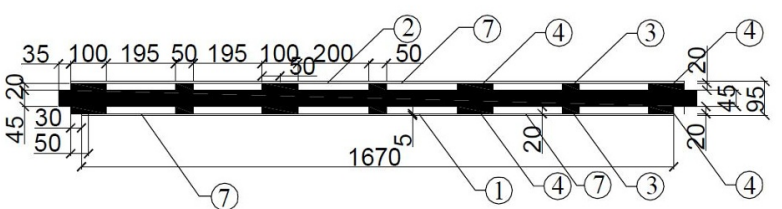

(e) Top view of Type-C/E

Fig. 2. Specimen configuration

Table 1. Specimen type.

\begin{tabular}{|c|c|}
\hline Specimen & Characteristic \\
\hline Type-A & Prototype \\
\hline Type-B & Thicken Sheathing (to 9 mm) \\
\hline Type-C & With X-bracings outside wood framing \\
\hline Type-D & With straw panel filling \\
\hline Type-E & $\begin{array}{c}\text { With X-bracings inside wood framing and straw } \\
\text { panel filling }\end{array}$ \\
\hline Type-F & $\begin{array}{c}\text { Add a screw at joints of wood framing and } \\
\text { sheathing }\end{array}$ \\
\hline Type-G & $\begin{array}{c}\text { Augment the diameter of screws at joints of wood } \\
\text { framing and sheathing (to 6.5 mm) }\end{array}$ \\
\hline
\end{tabular}

Table 2. Material table.

\begin{tabular}{|c|c|c|}
\hline Code & Name & Size(mm) \\
\hline$(1)$ & Sheathing1 & $1670 * 600 * 5(9)$ \\
\hline$(2)$ & Sheathing2 & $1730 * 600 * 5(9)$ \\
\hline$(3)$ & Longitudinal timber beam & $20 * 50 * 600$ \\
\hline$(4)$ & Longitudinal timber beam & $20 * 100 * 600$ \\
\hline$(5)$ & Lateral timber beam & $45 * 50 * 1800$ \\
\hline$(6)$ & Lateral timber beam & $45 * 25 * 1800$ \\
\hline$(7)$ & Steel X-bracing & - \\
\hline$(8)$ & Straw panels filling & - \\
\hline
\end{tabular}

\subsection{Experiment on full-scale CFSSW}

In the previous studies, a experiment of a full-scale newtype CFSSW has been conducted [10]. As shown in Fig.3, the full-scale CFSSW is composed of one steel upper beam, one steel bottom beam, three steel columns, three timber reinforcing plates and six CTWPs. Each steel column is composed of two C-section CFSs welded back-to-back to form an I-shaped section. The steel upper beam and the steel bottom beam are both single C- 
section CFSs of the same spec. The steel columns is connected with the steel upper beam and bottom beam by screws. The CTWPs inside the steel framework are composed of wood beams as inner frames, plasterboard and planks as sheathings. These CTWPs are inserted into the CFS framing directly from top to bottom through the fillisters of the steel columns. There is a groove at the bottom of CTWP, and it bulges on the top of CTWP. CTWPs are connected with tenon-and-mortise. The timber reinforcing plates are attached between the sheathings to reinforce their connection.

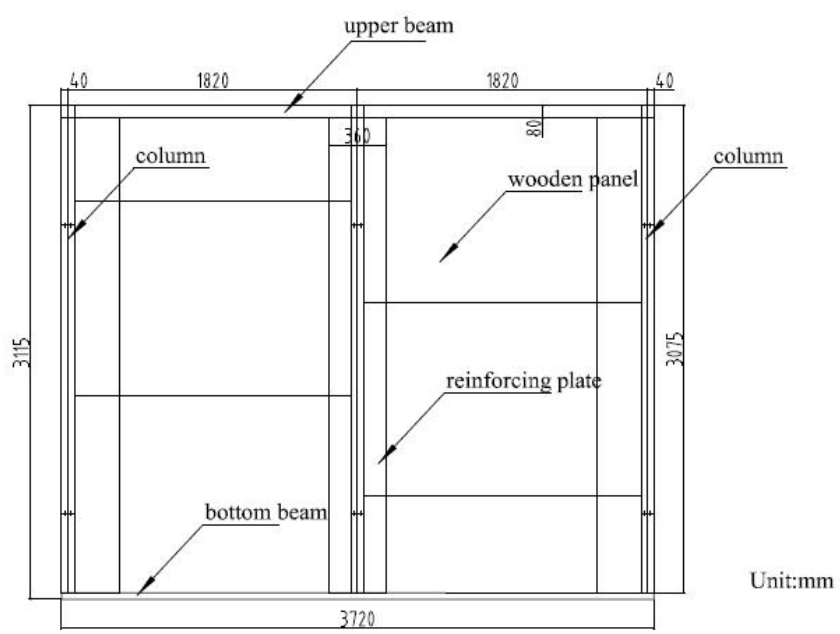

Fig. 3. Configuration of CFSSW.

The full-scale new-type CFSSW experiment was tested under monotonic loading. According to the results, it has favorable ductility, yet medium shear capacity compared with other prevailing CFSSWs. When failure happened, its cold-formed steel column could be inferred to remain safe while some CTWPs inside have lost strength. Based on the results of experiment, the failure mainly comes from the CTWPs, of which the inner timber beams and the screws. As shown in Fig.4, the sheathings bent and fractured, the inner timber beams cracked, and the screws slid and were pulled out.

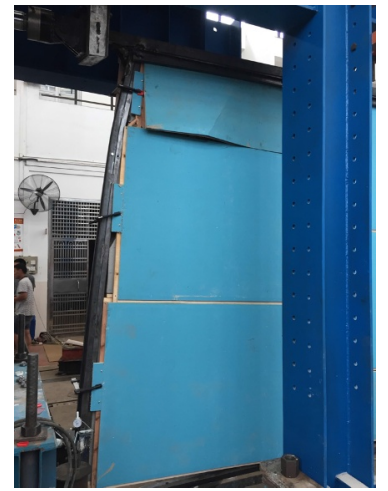

(a) Bending and fracture in the sheathings

Fig. 4. Failure type of CFSSW

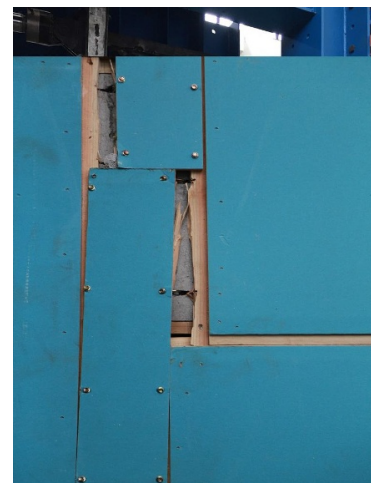

(b) Cracks in the inside longitudinal timber beams

\subsection{Experiment on CTWPs}

Fig.5 illustrates the setup of specimen in CTWP experiments.

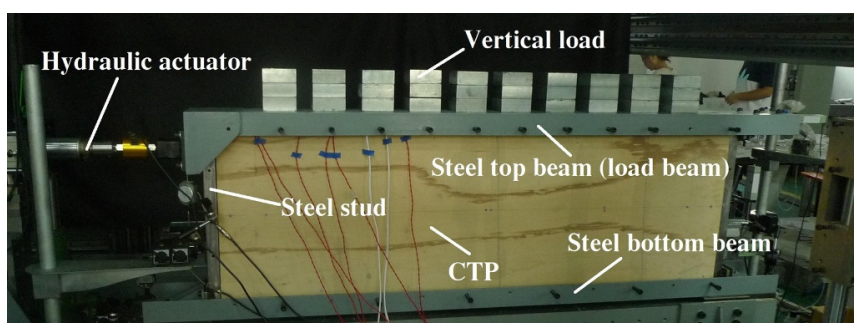

Fig. 5. Setup of the specimen test.

\subsubsection{Experiment on Type-B (thickening sheathing) and Type-C (outside $X$-bracings) CTWPS}

The difference between the Type-B CTWPs and the prototype (Type-A) is that the thickness of the sheathings is increased. And the change of Type-C CTWPs is adding the steel X-bracings and change of arrangement of the longitudinal beam. Influence of steel X-bracing [11] and the thickness of sheathings [9, 12] in CFSSWs have already been widely studied. These studies indicated that adding steel X-bracing and increasing the thickness of sheathings can both increase the lateral performance of CFSSWs.

According to the results of experiments, in monotonic and cyclic tests, failure of sheathing is most serious. The forming of sheathings changes from bending to fracture. With the loading increasing, the relative movement between timber framework and sheathings increased gradually, which made the slippage of screws happen. This slippage produced strong shear stress and bearing stress in both sheathings and longitudinal timber, which caused the cracks in longitudinal timber beams and bearing failure of sheathings. For Type-C, because of the pushing by sheathings and compressive stress, the steel X-bracings turned to bend. Comparing three panels' failure mode, Type-B CTWPs, the one with the thicker sheathings had the lowest degree of damage.

Under monotonic loading, the ultimate strength and the stiffness of Type-B and Type-C was similar and higher than prototype, also with good ductility. Under reversed cyclic loading, results indicate that Type-B and Type-C were better at the ability of energy absorption as well as shear capacity. Type-C has the highest ultimate strength and yield strength, and the shear capacity of two type panels are similar in two loading modes. Type-C's ductility ratio was the highest, which even higher than that in monotonic loading, that means steel X-bracings can improve the ductility. But because of larger deformation and failure of sheathings, the Type-C CTWPs are less suitable and practical compared with Type-B CTWPs. As a consequence, thickening sheathing is a more optimized method.

\subsubsection{Experiment on Type-D (straw-filled) and Type-E (inside $X$-bracings) CTWPs}

The structure of Type-D and Type E CTWPs have little different with the prototype, except for the filling and inside X-bracings. It is well known that straw offers a renewable and sustainable resource stream for a variety of construction products, including compressed board panels. The successful use of straw as thermal and sonar 
insulation within the external envelope of buildings has been demonstrated by the increasing number of successful contemporary projects around the world. Apart from that, Ash recommend its ductility, so it was considered as a method to advance CTWP's performance under lateral load as filler [14].

When designing this experiment, it is projected to examine the promotion on lateral performance of CTWPs with the exact two optimizations. However, until the test was set up and commenced it was found that the screws at the joints connecting the wood framing and sheathings were of poor quality. Some suffers from a wrong position while others share a smaller diameter (approximately $2 \mathrm{~mm}$ ) against the design. The prominent weakness in these joints led to inconsistency in performance with preceding experiment. During the experiments, those screws showed obvious slippage, of which the biggest displacement of screws reached about $50 \mathrm{~mm}$. Sheathings did not exhibit any detectable deformation and finally turned separated from the CTWPs with slippage of screws. The failure of specimens occurred soon after the fracture of screws while sheathings and wood framing showed few cracks. Moreover, the original horizontal or vertical timber beam became tilted correspondent with direction which the CTWP deflected in monotonic loading, suggesting how tenuous the connection was. However, even in the case of poor connection quality, specimen $\mathrm{D}$ and specimen $\mathrm{E}$ had better performance than the prototype.

Despite the fragile joints, Type-D CTWPs performed better than Type-A CTWPs both in monotonic and cyclic loading. Type-A CTWP's ductility ratio, shear capacity, dissipated energy and elastic shear stiffness were respectively $12 \%, 6 \%, 19 \%$ and $23 \%$ more than Type-A. That is to say, straw panel filling plays a remarkable role in CTWP's lateral loading resistance, which could absorb energy as well as serve as support or cushion.

Unlike Type-D, Type-E CTWPs hardly performed well. The X-bracing was constrained in a narrow space between wood framing and straw panel filling, leading to the worse capacity in dissipated energy in spite of the rise in shear capacity.

\subsubsection{Experiment on Type- $F$ (adding screw) and Type-G (augmenting screw diameter) CTWPs}

Based on previous investigation, it is found that the connection between members, particularly between wood framing and OSB sheathing, is crucial to performance of CTWPs since OSB board can serve to absorb energy as long as it is able to continuously deform. Two optimized CTWPs, Type-F and Type-G, were improved in connection between sheathing and wood framing, which was designed based on principles advocated in literature [15].

Type-A, Type-F and Type-G CTWPs were respectively tested under monotonic and cyclic loading with a vertical load of $960 \mathrm{~N}$ distributing on the upper beam uniformly. According to the results, their failure modes are similar to that of Type-A. However, the deformation extent of sheathing and wood framing were different. From the

results it was found that sheathing of Type-F CTWP deformed most among specimens while its wood framing stayed relatively intact. Type-A's sheathing bent and cracked least among three types of specimens. That is to say, Type-F is the one with relatively the best connection between sheathing and wood framing and Type-G's connection is not so effective as Type-F's, there exists a phenomenon that the stronger connection between sheathing and wood framing, the more sheathing contributes to the structure under lateral load. Besides, optimization in connection between sheathing and wood framing did help improve CTWP's performance under lateral load, which would be stated and analyzed next.

\section{Results and analysis}

\subsection{Failure type}

\subsubsection{Failure type of Full-scale CFSSW}

There are four kinds of failure in the monotonic loading of the full-scale CFSSW. (each failure type is shown in Fig. 4 and Fig. 6.) These failures could be observed sequentially with displacement.

a. Bending of sheathings. As the CFSSW became increasingly awry with displacement, the steel frame deformed together, causing one side of CTWPs under compression while the other side tension, therefore the sheathing of them turned wavy.

b. CTWP tilting away from the ground frame beam. The inconsistency between deformation of steel frame and CTWPs changed CTWPs to rotate instead of merely sideways.

c. Tear of welding spot on cold-formed steel column. The tilted deflection of CFSSW led to twist of the Cshaped steel column, by which tear of welding spot appeared consequentially.

d. Cracks in longitudinal timber beams. The continuously growing of rotation exemplified the pressure on CTWPs, and the beams inside them cracked.

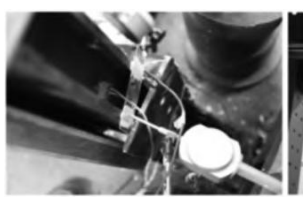

(a)Bending of sheathings (b)CTWP tilting away (c) from the ground frame spot cold-formed

Fig. 6. Failure type of CFSSW. beam

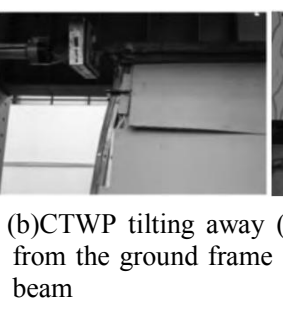

steel column

\subsubsection{Failure modes of CTWPS}

Seven different types of failure modes were observed as shown in Fig. 7. The failure modes of these specimen composite timber wall panels are similar except for the special case of poor screw quality. In the initial stage, the sheathing materials bended gradually with the applied force increasing. As for Type-C, the bending of steel Xbracings could also be observed at this stage. Then, the 
relative movement between sheathings and timber framework increased gradually, leading to the slippage of screws. The slippage of screws caused large shear stress and bearing stress in longitudinal timber beams and sheathings, leading to cracks in longitudinal timber beams and bearing failure in sheathings. Finally, the sheathing materials fractured when the sheathings bended at a large scale.

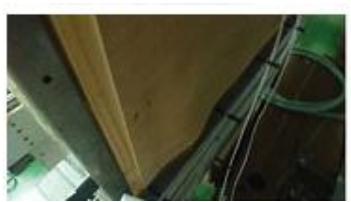

(c) Slippage of screws

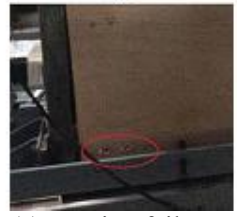

(e) Bearing failure of sheathings (a) Bending of sheathings
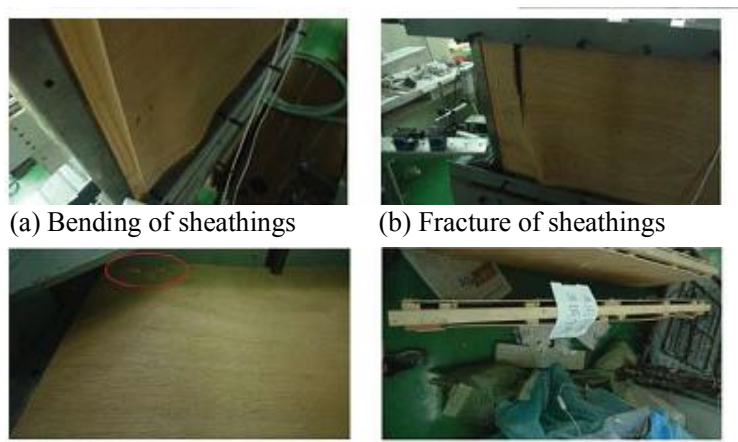

(b) Fracture of sheathings

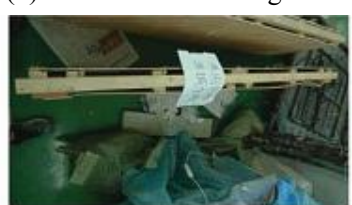

(d) Cracks in longitudinal beams

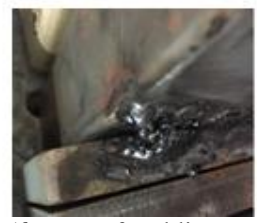

(f) Tear of welding $s$ (g) Bending of steel pot on cold-formed X-bracings steel column

Fig. 7. Failure modes of CTWPs.

a. Bending of sheathings. Initially, the sheathings were smooth, but it became wavy with time. The bending occurred mostly in the upper corner of the sheathings close to the applied load, and the lower corner of the other end of the sheathings. The deformation was largely caused by the relative movement of the sheathings and the inner timber framing.

b. Fracture of sheathings. With the increment of displacement and applied load, sheathings fractured in the curving area. The width of the cracks developed as the experiment progressed. The location of the cracks was not in the middle area of the panel, but at the corner of the panel.

c. Slippage of screws. The screws slippage was observed in all specimens and mainly occurred in the upper and lower part of the sheathings. Because of the relative movement of the sheathings and the inner timber framing, the displacement of the upper part was smaller than the inner timber framing, while the displacement of the lower part was larger than the inner timber framing. Therefore, as can be seen in (Fig. 6) (a, b, c), the screws in the upper part tilted towards the applied load, while the screws in the lower part tilted towards the opposite direction. If the deflection is overwhelming, the screws may get cut.

d. Cracks in longitudinal timber beams. The sheathings were attached to the inner timber framing by screws. When external forces were applied to the specimens, longitudinal timber beams were subjected to strong shear stress caused by screws, which led to the cracks. It was observed in the top and bottom area with screws penetrated in. e. Bearing failure of sheathings. The external forces were transferred between the inner timber framing and the sheathings through screws. Stress concentration phenomenon and bearing stress between the screws and sheathings occurred in the screw holes, which caused the bearing failure of the sheathings. This failure was obvious in the surrounding area of the screws in all the specimens.

f. Tear of welding spot on cold-formed steel column. The asymmetrical deflection of CTWPs under lateral loading cause non-uniform stress distribution in the coldformed steel column and twist of it, which leads to tear of welding spot.

g. Bending of steel X-bracings. Steel X-bracings in Type-C bended for two main reasons. Firstly, the bending of the sheathings pushed the steel X-bracings and made them to bend. Secondly, steel X-bracings were subjected to compressive stress, which made them to bend.

\subsection{Load-displacement curves}

As the quality of Type-D and Type-E CTWPs in the second CTWP experimental study are distinct from other specimens, their numerical results will thus not be demonstrated and compared with other experiments in the following.

\subsubsection{Full-scale CFSSW}

According to the results shown in Fig. 8, Table 3 and 4, this new-type CFSSW, which is relatively easy to construct, possesses medium shear capacity and ductility ratio while rather stronger deformation ability compared with other common CFSSW.

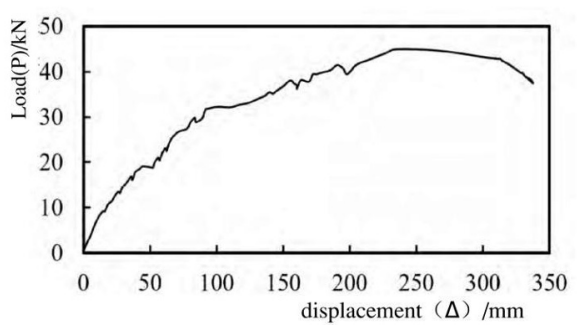

Fig. 8. $P$ - $\Delta$ curve for monotonic tests of CFSSW.

Table 3. Comparison of structural performance parameters with other literatures in monotonic tests of Full-scale CFSSW.

\begin{tabular}{|c|c|c|c|c|c|c|c|}
\hline \multicolumn{2}{|c|}{ Data source } & - & \multicolumn{2}{|c|}{$[19]$} & {$[20]$} & \multicolumn{2}{c|}{$[21]$} \\
\hline \multicolumn{2}{|c|}{ No. } & Type-A & BX-3 & BX-5 & BX-1 & WSC-1 & WDC-2 \\
\hline \multirow{2}{*}{ Structure } & SSGF & $\begin{array}{c}\text { One- } \\
\text { side } \\
\text { OSB } \\
\text { board }\end{array}$ & $\begin{array}{c}\text { Plaste } \\
\text { r+OS } \\
\text { B } \\
\text { board }\end{array}$ & $\begin{array}{c}\text { Plaster } \\
\text { +OSB } \\
\text { board }\end{array}$ & $\begin{array}{c}\text { Plaster } \\
\text { +OSB } \\
\text { board }\end{array}$ & $\begin{array}{c}\text { Plaster } \\
\text { +OSB } \\
\text { board }\end{array}$ \\
\hline \multirow{2}{*}{ Yield load } & $\boldsymbol{P}_{\boldsymbol{y}} / \mathbf{k N}$ & 37.22 & 21.5 & 29.1 & 44.02 & 53.56 & 65.06 \\
\cline { 2 - 9 } & $\boldsymbol{\Delta}_{\boldsymbol{y}} / \mathbf{m m}$ & 157.2 & 23.9 & 19.6 & 21.93 & 20.84 & 19.45 \\
\hline \multirow{2}{*}{$\begin{array}{c}\text { Ultimate } \\
\text { load }\end{array}$} & $\boldsymbol{P}_{\max } / \mathbf{k N}$ & 44.99 & 26.84 & 34.9 & 53.19 & 60.74 & 76.1 \\
\cline { 2 - 9 } & $\boldsymbol{A}_{\max } / \mathbf{m m}$ & 268.4 & 51.21 & 59.6 & - & 39.25 & 35.12 \\
\hline \multirow{2}{*}{$\begin{array}{c}\text { Failure } \\
\text { load }\end{array}$} & $\boldsymbol{P}_{u} / \mathbf{k N}$ & 38.24 & 22.81 & 29.7 & 45.28 & 52.13 & 64.69 \\
\cline { 2 - 9 } & $\boldsymbol{\Delta}_{\boldsymbol{u}} / \mathbf{m m}$ & 331.9 & 68 & 74 & 67.5 & 50.67 & 47.33 \\
\hline \multicolumn{2}{|c|}{ Ductility ratio $\boldsymbol{\mu}$} & 2.11 & 2.85 & 3.78 & 3.08 & 2.44 & 2.45 \\
\hline \multirow{2}{*}{ Shear capacity $\mathbf{V}_{\max } / \mathbf{k N}$} & 11.97 & 11.18 & 14.5 & 13.3 & 11.91 & 12.76 \\
\hline
\end{tabular}

Table 4. Component deformation capacity table.. 


\begin{tabular}{|c|c|c|c|c|c|}
\hline $\begin{array}{c}\text { Specimen } \\
\text { Number }\end{array}$ & $\boldsymbol{\Delta}_{\text {LIMIT }} / \mathbf{m m}$ & $\boldsymbol{\Delta}_{\max } / \mathbf{m m}$ & $\boldsymbol{\Delta}_{u} / \mathbf{m m}$ & $\boldsymbol{\Delta}_{\boldsymbol{u}} / \mathbf{\Delta l i m i t}$ & $\begin{array}{c}\text { Deformation } \\
\text { capacity }\end{array}$ \\
\hline Type-A & 80.18 & 269.0 & 340.1 & 4.24 & high \\
\hline
\end{tabular}

\subsubsection{Optimization of CTWP}

\subsubsection{Behavior under monotonic loading}

The lateral in-plane shear load $(P)$ versus the net inplane displacement $(\Delta)$ of all types of specimens we test are demonstrated in Fig. 9.

We applied equivalent energy-plastic (EEEP) bi-linear model according to the AISI standard [16] (Fig.10) in the computation of structure performance parameters shown in Table 5 and Table 6. Dissipated energy $(E)$ represents the amount of energy consumed by a specimen until failure, which is the area under $P-\Delta$ curve for monotonic tests. Elastic shear stiffness $\left(K_{\mathrm{e}}\right)$ is defined as a slope measured by the ratio of the resisted shear load to the corresponding displacement, indicating the resistance to deformation of a specimen in the elastic state [16]. The shear capacity is defined as the ultimate strength per unit length [17]. The fundamental definition of ductility ratio is the ratio of ultimate displacement and the yield displacement [9].

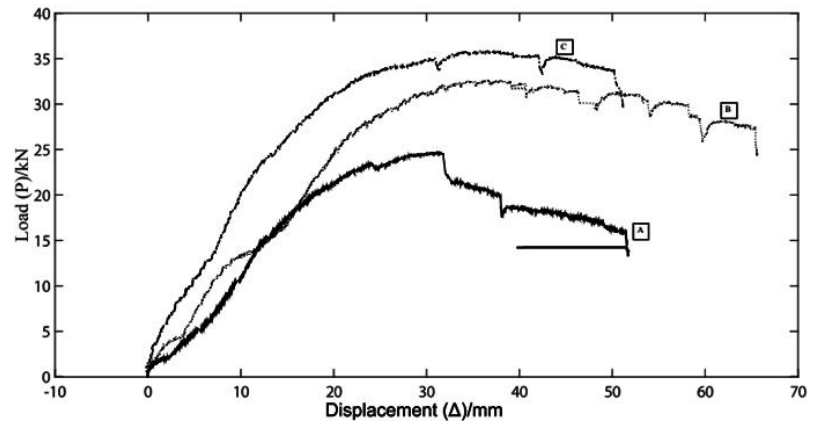

(a) Type-A, B, C

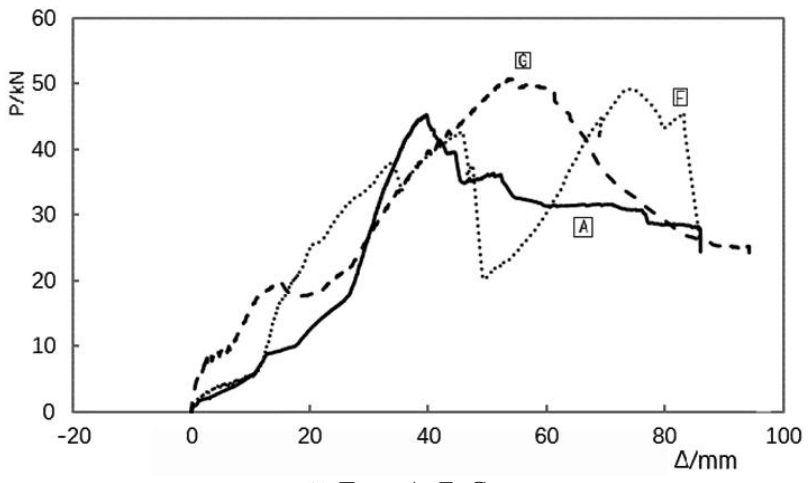

(b) Type-A, F, G

Fig. 9. $P$ - $\triangle$ curve for monotonic tests.

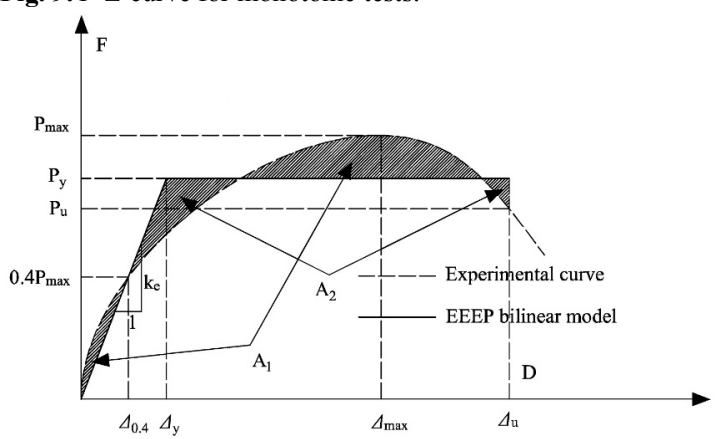

Fig. 10. EEEP analysis model for monotonic tests.
Based on the results of two experiments, as shown Table 5 and 6 , it was concluded that each optimization's improvement to Type-A, the prototype CTWP, in Table 7 to compare their optimization effect:

a. Regarding the shear capacity, all types of optimization have a larger shear capacity than the prototype. Type-G is the one with the largest growth in shear capacity (79.01\%) and Type-C is the second with $50.19 \%$ growth.

b. In the yield state, Type-C could shoulder relatively large shear load while staying the lowest displacement, corresponding with its highest rise in $K_{\mathrm{e}}$.

c. The increase in ductility ratio and dissipated energy of Type-C panels are also the highest among all optimization. It suggests that adding steel bracing could serve a better performance in ductility and energy dissipation under monotonic loading.

d. The method of adding screw to improve the stiffness turns out that excessive stiffness of nails leads to sudden stiffness drop as demonstrated in the figure, which means the structure is not stable enough bringing greatly changes of structural response.

Table 5. Comparison of structural performance parameters in monotonic tests of Type-A, B, C.

\begin{tabular}{|c|c|c|c|c|}
\hline \multicolumn{2}{|c|}{ Specimen } & Type-A & Type-B & Type-C \\
\hline \multirow{2}{*}{ Yield state } & $\boldsymbol{P}_{\boldsymbol{y}} / \mathbf{k N}$ & 22.27 & 30.02 & 33.06 \\
\cline { 2 - 5 } & $\boldsymbol{\Delta}_{\boldsymbol{y}} / \mathbf{m m}$ & 19.28 & 14.22 & 12.21 \\
\hline \multirow{2}{*}{ Ultimate state } & $\boldsymbol{P}_{\boldsymbol{m a x}} / \mathbf{k N}$ & 23.6 & 32.42 & 35.44 \\
\cline { 2 - 5 } & $\boldsymbol{\Delta}_{\max } / \mathbf{m m}$ & 23.97 & 25.52 & 32.42 \\
\hline \multirow{2}{*}{ Failure state } & $\boldsymbol{P}_{\boldsymbol{u}} / \mathbf{k N}$ & 18.88 & 25.93 & 28.36 \\
\cline { 2 - 5 } & $\boldsymbol{\Delta}_{\boldsymbol{u}} / \mathbf{m m}$ & 37.02 & 46.83 & 42.53 \\
\hline Ductility Ratio $\boldsymbol{\mu}=\boldsymbol{\Delta}_{\boldsymbol{u}} / \boldsymbol{\Delta}_{\boldsymbol{y}}$ & 1.92 & 3.29 & 3.48 \\
\hline \multicolumn{2}{|c|}{ Dissipated energy $\boldsymbol{E} / \mathbf{J}$} & 609.75 & 1192.39 & 1204.21 \\
\hline \multicolumn{2}{|c|}{$\boldsymbol{K}_{\boldsymbol{e}} / \mathbf{k N} \cdot \mathbf{m m}^{-\mathbf{1}}$} & 1.16 & 2.11 & 2.7 \\
\hline \multicolumn{2}{|c|}{ Shear $\mathbf{c a p a c i t y} / \mathbf{k N} \cdot \mathbf{m}^{-\mathbf{1}}$} & 13.11 & 18.01 & 19.69 \\
\hline
\end{tabular}

Table 6. Comparation of structural performance parameters in monotonic tests of Type-A, F, G.

\begin{tabular}{|c|c|c|c|c|}
\hline \multicolumn{2}{|c|}{ Specimen } & Type-A & Type-F & Type-G \\
\hline \multirow{2}{*}{ Yield state } & $P_{y} / \mathbf{k N}$ & 28.79 & 21.1 & 34.34 \\
\hline & $\Delta_{y} / \mathbf{m m}$ & 39.2 & 34.7 & 43.1 \\
\hline \multirow{2}{*}{ Ultimate state } & $\begin{array}{l}P_{\max } \\
/ \mathbf{k N} \\
\end{array}$ & 33.91 & 25.43 & 41.29 \\
\hline & $\begin{array}{l}\Delta_{\max } \\
/ \mathrm{mm}\end{array}$ & 46.43 & 40.57 & 51.19 \\
\hline \multirow{2}{*}{ Failure state } & $\begin{array}{c}P_{u} \\
/ \mathbf{k N}\end{array}$ & 28.82 & 21.62 & 35.1 \\
\hline & $\begin{array}{c}\begin{array}{c}A_{u} \\
/ \mathrm{mm}\end{array} \\
\end{array}$ & 51.55 & 44.82 & 57.04 \\
\hline \multicolumn{2}{|c|}{ Ductility Ratio $\mu=\Delta_{u} / \Delta_{y}$} & 1.32 & 1.29 & 1.32 \\
\hline \multicolumn{2}{|c|}{$\begin{array}{c}\text { Equivalent Viscous Damping } \\
\text { Ratio } v_{e q} \\
\end{array}$} & 0.14 & 0.13 & 0.15 \\
\hline \multicolumn{2}{|c|}{$K_{e} / \mathbf{k N} \times \mathbf{m m}^{-1}$} & 0.73 & 0.61 & 0.8 \\
\hline \multicolumn{2}{|c|}{ Shear capacity $/ \mathbf{k N} \times \mathbf{m}^{-1}$} & 18.84 & 14.13 & 22.94 \\
\hline
\end{tabular}

Table 7. increase in structural performance parameters in monotonic tests compared with Type-A.

\begin{tabular}{|c|c|c|c|c|}
\hline \multirow{3}{*}{ Specimen } & \multicolumn{4}{|c|}{ optimization effect } \\
\cline { 2 - 5 } & $\begin{array}{c}\text { Ductility ratio } \\
\mu=\Delta \mathbf{u} / \Delta \mathbf{y}\end{array}$ & $\begin{array}{c}\text { Equivalent } \\
\text { viscous }\end{array}$ & $\begin{array}{c}\mathrm{K}_{\mathrm{e}} / \mathbf{k N} \\
\times \mathbf{m m}^{-1}\end{array}$ & $\begin{array}{c}\text { Shear } \\
\text { capacity }\end{array}$ \\
\hline
\end{tabular}




\begin{tabular}{|c|c|c|c|c|}
\hline & & $\begin{array}{c}\text { damping } \\
\text { ratio veq }_{\text {eq }}\end{array}$ & & $/ \mathbf{k N \times \mathbf { m } ^ { - 1 }}$ \\
\hline Type-B & $47.42 \%$ & $7.69 \%$ & $64.86 \%$ & $116.98 \%$ \\
\hline Type-C & $67.61 \%$ & $7.69 \%$ & $91.22 \%$ & $144.69 \%$ \\
\hline Type-F & $-1.78 \%$ & $0.00 \%$ & $-17.21 \%$ & $-25.01 \%$ \\
\hline Type-G & $2.46 \%$ & $14.29 \%$ & $31.03 \%$ & $62.37 \%$ \\
\hline
\end{tabular}

\subsubsection{Behavior under reversed cyclic loading}

Fig. 11 illustrates the load-displacement $(P-\Delta)$ hysteretic and cyclic loading envelop curves of all specimens, along with the monotonic ones.

Similarly, the structural performance under reversed cyclic loading are also calculated according to EEEP model, given results in Table 8 and 9. The equivalent viscous damping ratio $\left(\gamma_{\mathrm{eq}}\right)$ is adopted to evaluate the energy dissipation capacity based on Chopra's research [18].

Also, in order to compare each optimization's effect, Table 10 is drawn based on two experiments results shown in Table A and B. We could conclude that:

a. Type-C had the highest growth in shear capacity by $144.69 \%$. Compared with the values in monotonic tests, two optimized panels, Type-B and Type-C had similar shear capacity in two loading modes, while the shear capacity of the original panel was $54.6 \%$ lower in the cyclic tests. It indicates that under cyclic loading, considerable strength degradation occurred in Type-A, but it was not obvious in Type-B and Type-C. Nonetheless, Type-F showed decrease in capacity, which implies that overextend of connection between sheathing and wood framing could strict the performance of CTWP under reversed cyclic loading.

b. The increase in ductility ratio of Type-C was the highest in all specimens (67.61\%), and its ductility ratio is even higher than the data in monotonic loading, which indicates that steel X-bracings increased the ductility of the panel under cyclic loading. As for Type-G, the advance in ductility ratios under cyclic tests was marginal, and Type-F's even lower than Type-A.

c. The equivalent viscous damping ratio of all specimens are approximate, ranged from 0.13 to 0.15 . The values of Type-B and Type-C were nearly the same and they both $8 \%$ were higher while Type-G increase by $14 \%$, as much as almost double times of preceding ones. It shows that thick sheathings and steel X-bracings can increase the property of the energy dissipation but improving in connection between them could do even better.

e. Stiffness degradation is often used to evaluate the seismic performance of composite wallboard members [18]. Relative stiffness is defined as the ratio of equivalent stiffness to initial stiffness. Equivalent stiffness is the slope of the line connecting a point on the envelope curve and the origin, while initial stiffness is the lateral stiffness in the elastic stage. The ratio of the displacement of a point on the envelope to the failure displacement $\left(\Delta_{\mathrm{u}}\right)$ is defined as relative displacement. As can be seen from Fig. 12, the overall tendency of stiffness change of all specimens is similar, that is, it reduced sharply during the initial stage and then decreased gradually until failure, except Type-G's, which gradually climbed $40 \%$ higher and went down later. In the initial stage, the decrease of stiffness of Type-A and Type-F was both significant, while that of Type-B, Type-C and Type-G were 20 percent less than the Type-A. In the failure stage, equivalent stiffness of all specimens decreased to only $20 \%$ of the initial stiffness while Type-G remained $40 \%$. The overall trend of stiffness degradation for Type-A was much more significant than Type-B and Type-C, indicating that adding steel $\mathrm{X}$-bracings and increasing the thickness of sheathing materials can increase the seismic performance. The distinction of overall trends of stiffness degradation for Type-G illustrates that proper promotion in connection between sheathing and wood framing has prepossessing effect on improving the stiffness degradation corresponding with the primary failure in these connections shown in precedent experiments.

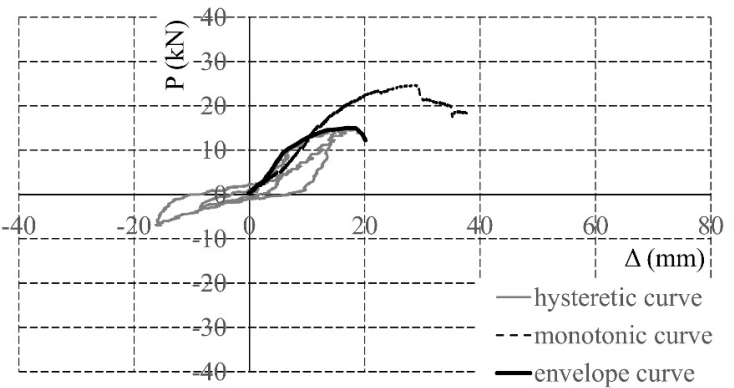

(a) Type-A

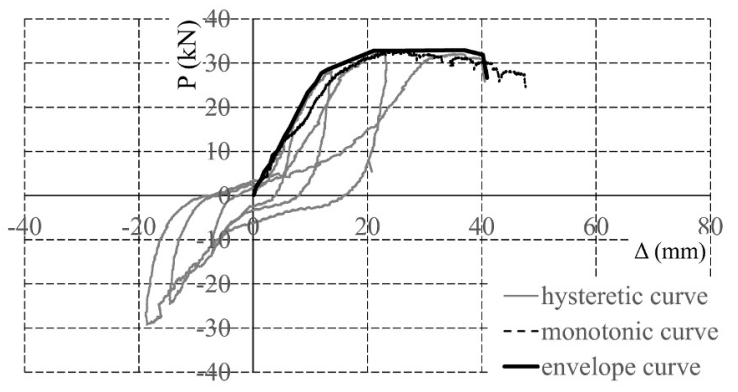

(b) Type-B

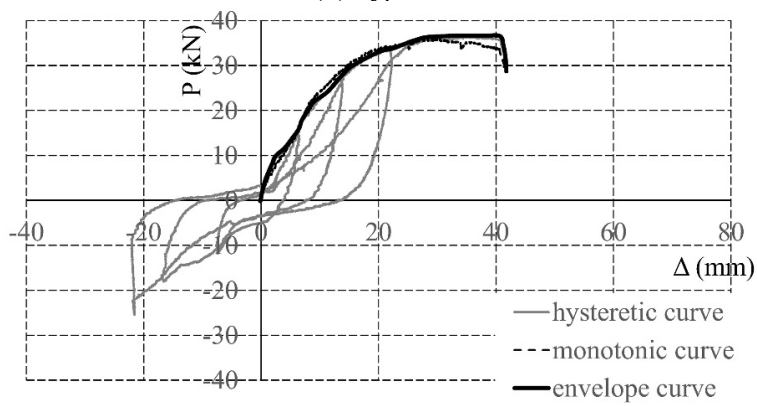

(c) Type-C 


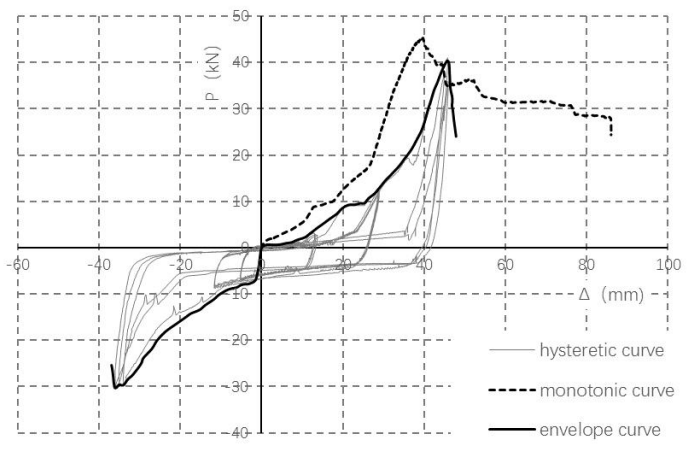

(d) Type-A

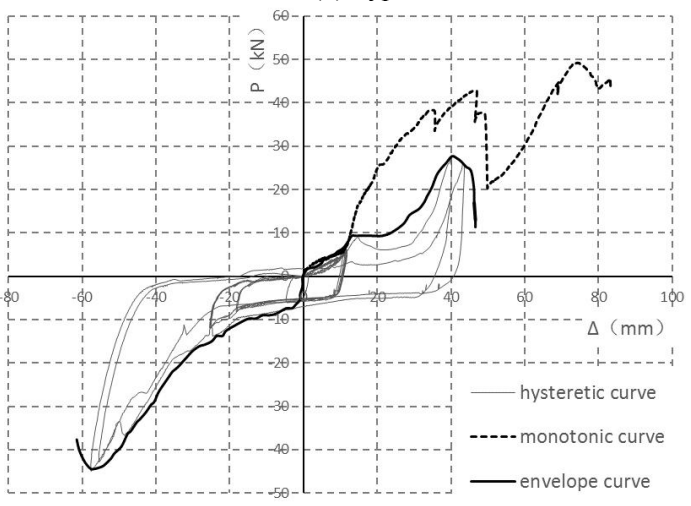

(e) Type-F

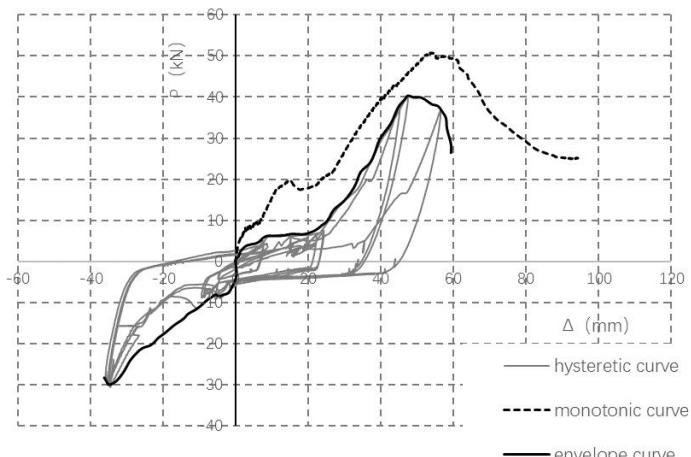

(f) Type-G

Fig. 11. $P$ - $\Delta$ curves for cyclic tests.

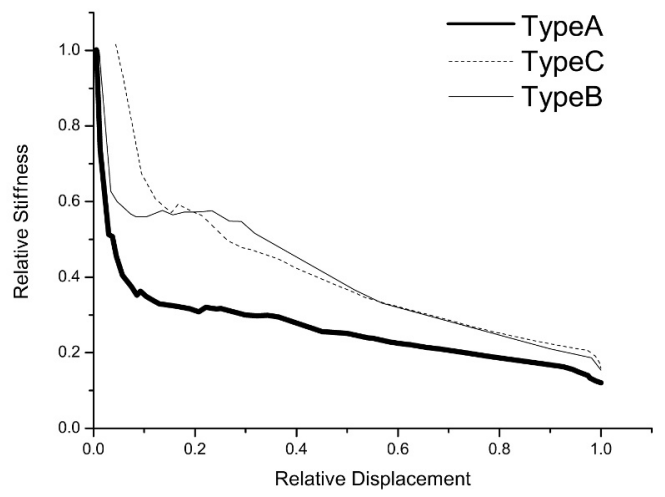

(a) Type-A, B, C

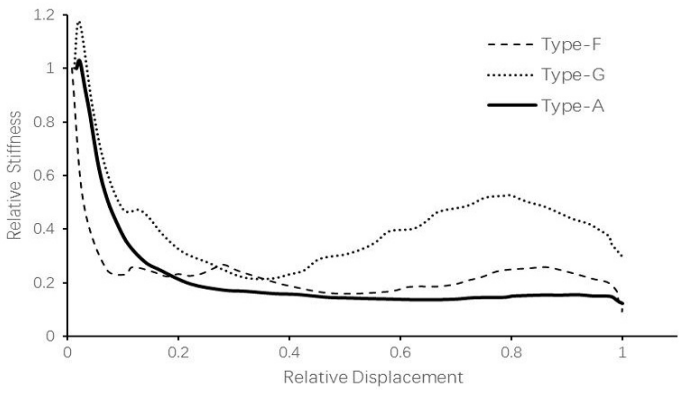

(b) Type-A, F, G

Fig. 12. Comparison of stiffness degradation.

Table 8. Comparison of structural performance parameters in cyclic tests of Type-A, B, C.

\begin{tabular}{|c|c|c|c|c|}
\hline \multicolumn{2}{|c|}{ Specimen } & Type-A & Type-B & Type-C \\
\hline \multirow{2}{*}{ Yield state } & $P_{y} / \mathbf{k N}$ & 14.01 & 31.81 & 33.37 \\
\hline & $\Delta_{y} / \mathbf{m m}$ & 9.46 & 13.03 & 11.79 \\
\hline \multirow{2}{*}{ Ultimate state } & $P_{\max } / \mathbf{k N}$ & 15.27 & 33.12 & 37.35 \\
\hline & $\Delta_{\max } / \mathbf{m m}$ & 17.42 & 20.07 & 36.09 \\
\hline \multirow{2}{*}{ Failure state } & $P_{u} / \mathbf{k N}$ & 12.21 & 26.49 & 29.88 \\
\hline & $\Delta_{u} / \mathbf{m m}$ & 20.15 & 40.92 & 42.12 \\
\hline \multicolumn{2}{|c|}{ Ductility ratio $\mu=\Delta_{u} / \Delta_{y}$} & 2.13 & 3.14 & 3.57 \\
\hline \multicolumn{2}{|c|}{$\begin{array}{c}\begin{array}{c}\text { Equivalent Viscous Damping } \\
\text { ratio }_{\mathrm{eq}}\end{array} \\
\end{array}$} & 0.13 & 0.14 & 0.14 \\
\hline \multicolumn{2}{|c|}{$K_{e} / \mathbf{k N} \times \mathbf{m m}^{-1}$} & 1.48 & 2.44 & 2.83 \\
\hline \multicolumn{2}{|c|}{ Shear Capacity $/ \mathbf{k N} \times \mathbf{m}^{-1}$} & 8.48 & 18.4 & 20.75 \\
\hline
\end{tabular}

Table 9. Comparison of structural performance parameters in cyclic tests of Type-A, F, G.

\begin{tabular}{|c|c|c|c|c|}
\hline \multicolumn{2}{|c|}{ Specimen } & Type-A & Type-F & Type-G \\
\hline \multirow{2}{*}{ Yield State } & $P_{y} / \mathbf{k N}$ & 28.79 & 21.1 & 34.34 \\
\hline & $\Delta_{y} / \mathrm{mm}$ & 39.2 & 34.7 & 43.1 \\
\hline \multirow{2}{*}{ Ultimate State } & $P_{\max } / \mathbf{k N}$ & 33.91 & 25.43 & 41.29 \\
\hline & $\Delta_{\max } / \mathbf{m m}$ & 46.43 & 40.57 & 51.19 \\
\hline \multirow{2}{*}{ Failure State } & $P_{u} / \mathbf{k N}$ & 28.82 & 21.62 & 35.1 \\
\hline & $\Delta_{u} / \mathbf{m m}$ & 51.55 & 44.82 & 57.04 \\
\hline \multicolumn{2}{|c|}{ Ductility Ratio $\mu=\Delta_{u} / \Delta_{y}$} & 1.32 & 1.29 & 1.32 \\
\hline \multicolumn{2}{|c|}{$\begin{array}{c}\begin{array}{c}\text { EquivalentViscous Damping Ratio } \\
v_{e q}\end{array} \\
\end{array}$} & 0.14 & 0.13 & 0.15 \\
\hline \multicolumn{2}{|c|}{$K_{e} / \mathbf{k N} \times \mathbf{m m}^{-1}$} & 0.73 & 0.61 & 0.8 \\
\hline \multicolumn{2}{|c|}{ Shear Capacity $/ \mathbf{k N} \times \mathbf{m}^{-1}$} & 18.84 & 14.13 & 22.94 \\
\hline
\end{tabular}

Table 10. increase in structural performance parameters in cyclic tests compared with Type-A.

\begin{tabular}{|c|c|c|c|c|}
\hline \multirow{2}{*}{$\begin{array}{c}\text { Specime } \\
\mathbf{n}\end{array}$} & $\begin{array}{c}\text { Ductility ratio } \\
\boldsymbol{\mu}=\mathbf{\Delta u} / \mathbf{\Delta y}\end{array}$ & $\begin{array}{c}\text { Equivale } \\
\mathbf{n t} \\
\mathbf{v i s c o u s} \\
\mathbf{d a m p i n g} \\
\text { ratio Ueq }\end{array}$ & $\begin{array}{c}\mathbf{K} \\
\mathbf{K}\end{array}$ & $\begin{array}{c}\text { Shear } \\
\mathbf{c a p a c i t y} \\
/ \mathbf{k N} \times \mathbf{m m}^{-1} \\
\mathbf{1}\end{array}$ \\
\hline Type-B & $47.42 \%$ & $7.69 \%$ & $64.86 \%$ & $116.98 \%$ \\
\hline Type-C & $67.61 \%$ & $7.69 \%$ & $91.22 \%$ & $144.69 \%$ \\
\hline Type-F & $-1.78 \%$ & $0.00 \%$ & $-17.21 \%$ & $-25.01 \%$ \\
\hline Type-G & $2.46 \%$ & $14.29 \%$ & $31.03 \%$ & $62.37 \%$ \\
\hline
\end{tabular}

4 Conclusion 
In a nutshell, we have studied the mechanic properties of the full-scale new-type CFSSW under in-plane monotonic loading and then considered four methods to improve the performance of CTWPs, including increasing the thickness of sheathing materials, adding steel X-bracings, adding straw panel filler and improving connections between sheathing and wood framing of CTWP, and seven types of specimens were tested under both monotonic and reversed cyclic loading. Based on the results, it can be concluded that:

1. The new-type CFSSW is easy to construct and has medium shear capacity as well as ductility ratio but better deformation ability compared with other prevailing CFSSWs. When failure happened, its coldformed steel column could be inferred to remain safe while some CTWPs inside have lost strength.

2. The failure modes of all CTWP specimens are similar: the bending of sheathings (the bending of steel $\mathrm{X}$-bracings in Type-C and Type-E), the slippage of screws (leading to the cracks in longitudinal timber beams and the bearing failure of sheathings), along with the tear of welding spot on cold-formed steel column, followed by the fracture of sheathings.

3. Comparing the failure modes among all kinds of panels in each experiment, the panel with the thicker sheathings had a lower degree of damage and firmer connection between sheathing and wood framing could help increase sheathing's structural contribution and protect framing of CTWP.

4. All four optimize methods we adopted could improve the performance of CTWP under both monotonic and cyclic loading. Adding X-bracings has the overall best effect of improvements among all optimization specimens under both monotonic and cyclic loading and increasing the thickness of sheathing materials is the second. Yet improving the connection between sheathing and wood framing by augmenting the diameter of screws has the best optimize effect in shear capacity under monotonic loading as well as equivalent viscous damping ratio and stiffness degradation under cyclic loading.

5. According to the results of experiments, the lateral capacity of the new-type CFSSW is mainly determined by CTWPs and the connection between CTWPs and cold-formed steel framework, which is a crucial factor requiring further investigation.

\section{References}

[1] W. Mowrtage, N.H. Yel, B. Pekmezci and H.N. Atahan, Thin Wall Struct., vol. 60, pp. 145-153, (2012).

[2] E. Baran and C. Alica, Construct. Steel Res., vol. 79, pp.1-8, (2012).

[3] Y.S. Tian, J. Wang, T.J. Lu and C.Y. Barlow, Thin Wall Struct., vol. 42, pp. 557-573, (2004).

[4] L.C. Vieira Jr, Y. Shifferaw, and B.W. Schafer, Construct. Steel Res.,vol . 67, pp. 1554-1566, (2011).
[5] Y.S. Tian, J. Wang and T.J. Lu, Thin Wall Struct., vol. 45, pp. 537-551, (2007).

[6] M. Nithyadharan and V. Kalyanaraman, Thin Wall Struct., vol. 60, pp. 12-23, (2010).

[7] C.L. Pan and M.Y. Shan, Thin Wall Struct., vol. 49, pp. 363-370,2011.272 The Open Construction and Building Technology Journal, Volume 11 He et al, (2017)

[8] J.H. Ye, X.X. Wang, H.Y. Jia, and M.Y. Zhao, Thin Wall Struct., vol. 92, pp. 146-159, (2015).

[9] W. Seim, M. Kramar, T. Pazlar, and T. Vogt, J. Struct. Eng., vol. 142, no. 4, p. E4015004, (2016).

[10] J. Li, Z.H. Xie, M.K. Li, J.Q. Lan, and Y.L. Huang, Build. Struct., vol. 46, pp. 604-609, (2016).

[11] R. Serrette, and K. Ogunfunmi, J. Struct. Eng., vol. 122, pp. 383-389, (1996).

[12] N. Balh, J. DaBreo, C. Ong-Tone, K. ElSaloussy, C. Yu and C.A. Rogers, Thin Wall Struct., vol. 75, pp. 76-86, (2014).

[13] J.He., J. Li., Z.Y. Xin and W.A. Jiang. J. Open Construct. Build. Technol., 11(1), 255273. (2017)

[14] C. Ash, M. Ascheim. Ecobuild Network (2003).

[15] A.O. Olorunnisola, Design of Structural Elements with Tropical Hardwoods, (2017).

[16] "North American standard for cold-formed steel framing-lateral design", AISI S213-07, (2007).

[17] "Technical specification for low-rise coldformed thin-walled steel buildings", JGJ 2272011. (In Chinese)

[18] S.C. Ma, and N. Jiang, Mater. Sturct., vol. 8, no. 6, pp. 3732-3753, (2015).

[19] T.H. Zhou, Y. Shi and B.K. He., J. Xi'an Uni. Architect. Techno. : Nat. Sci. Ed, (1): 83-88. (2016).

[20] L.F. Guo, J. Xi'an Uni. Architect. Technol. : Nat. Sci. Ed, (2004).

[21] Z.G. Huang . J. Xi'an Uni. Architect. Technol.: Nat. Sci. Ed, (2011). 